\title{
Short communication: Analysis of milk yield and composition for dairy heifers limit-fed lower forage diets during the rearing period ${ }^{1}$
}

\author{
G. I. Zanton and A. J. Heinrichs ${ }^{2}$ \\ Department of Dairy and Animal Science, The Pennsylvania State University, University Park 16802
}

\begin{abstract}
Methods to improve feed efficiency in dairy heifers have been studied that employ limit feeding and high concentrate or highly digestible diet ingredients. To date, the published studies have used differing daily gains, diet components, and management systems. All of these studies have had limited numbers of animals, which limits the power of each study by itself. The objective of this analysis was to evaluate, using all available studies, the overall effect of limit feeding dairy heifers during the rearing phase on milk production and composition during the first lactation. To accomplish this objective, responses from published experiments were analyzed using random effects meta-analytic procedures. The results of this analysis confirmed the results of the individual experiments in that no significant differences were found in lactation performance between the limitfed, lower forage diets and the higher forage control diets. Heterogeneity of results between experiments was low to moderate for the response variables evaluated, indicating that the results were reasonably consistent among the trials. Limit feeding of higher concentrate diets represents a viable alternative to traditional high forage heifer feeding systems when environmental or economic conditions favor these systems.
\end{abstract}

Key words: heifer, limit-fed, milk production

The contribution of the growing dairy heifer to the feed, economic, and environmental management of dairy farms can be considerable. Strategies that reduce the feed usage, cost of production, and environmental impact of the dairy heifer would positively benefit dairy producers and enhance resources available for the management of the lactating dairy cow. One potential nutritional management strategy that may alter the feed and environmental budgets of the dairy heifer operation is the concept of limit feeding. Recent research

\footnotetext{
Received April 12, 2010.

Accepted June 21, 2010.

${ }^{1}$ This research was a component of NC-1042, Management Systems to Improve the Economic and Environmental Sustainability of Dairy Enterprises.

${ }^{2}$ Corresponding author: ajh@psu.edu
}

has demonstrated that when dairy heifers are grown under a limit feeding protocol, with diets of enhanced energy density, feed and forage intake is reduced and fecal or total manure output can be substantially reduced (Hill et al., 2007; Hoffman et al., 2007; Moody et al., 2007; Zanton and Heinrichs, 2009a). Previous research has also demonstrated that development of the mammary parenchyma before puberty (Sejrsen and Foldager, 1992) and DMI during lactation (Hof and Lenaers, 1984), after limit feeding high concentrate diets during the rearing period, was not different from the heifers fed the control, higher forage diet.

Additionally in all studies, the milk production of the limit-fed heifers did not differ from that of heifers fed a control diet for a similar level of ADG (Hof and Lenaers, 1984; Sejrsen and Foldager, 1992; Carson et al., 2000; Hoffman et al., 2007; Zanton and Heinrichs, 2007). In each of these cases, however, the heifers that were limit-fed produced numerically greater quantities of milk of similar composition. Given the limited power of any individual experiment, it is of interest whether the numerical increase in milk production is a true increase that would be observed on dairy farms raising a large number of dairy heifers. Only the experiment of Sejrsen and Foldager (1992) observed the concentration of a component of milk (protein concentration) to be significantly altered, whereas Zanton and Heinrichs (2007) observed significant differences in milk fat yield. In contrast, recent data from this laboratory (Lascano et al., 2009), although not significantly different, showed a numerical reduction in milk yield. For limit feeding to be a management practice that can be applied on dairy farms, the expected productivity response during subsequent lactations must be known. Therefore, the objective of this analysis was to evaluate the effect of limit feeding during the rearing phase on milk production and composition during the first lactation.

To accomplish this objective, responses from the available experiments were analyzed using random effects meta-analytic procedures. It is known that limit feeding a common diet can result in different levels of ADG, and differences in ADG (in the prepubertal phase of rearing at least) are known to affect milk production (Zanton and Heinrichs, 2005). Therefore, to be included 
Table 1. Summary of experiments that entered into random effects meta-analysis ${ }^{1}$

\begin{tabular}{|c|c|c|c|c|c|c|}
\hline Reference & $n^{2}$ & Breed & $\begin{array}{l}\text { Heifer phase } \\
\text { feeding period }\end{array}$ & $\begin{array}{l}\text { Forage, } \\
\text { \% DM }\end{array}$ & $\begin{array}{c}\mathrm{ADG} \pm \\
\mathrm{SEM}, \mathrm{g} / \mathrm{d}\end{array}$ & $\begin{array}{l}\text { Milk yield } \pm \\
\text { SEM, kg/d }\end{array}$ \\
\hline \multirow[t]{2}{*}{ Lascano et al., 2009} & 13 & \multirow[t]{2}{*}{ Holstein } & \multirow[t]{2}{*}{8 mo to calving } & 80 & $803 \pm 15$ & $35.5 \pm 0.9$ \\
\hline & 10 & & & 40 & $803 \pm 15$ & $33.1 \pm 0.9$ \\
\hline & 17 & & & 25 & $827 \pm 10$ & $28.7 \pm 1.3$ \\
\hline \multirow[t]{2}{*}{ Hoffman et al., 2007} & 3 (15) & \multirow[t]{2}{*}{ Holstein } & \multirow[t]{2}{*}{ Postpubertal } & 94 & $754 \pm 64$ & $30.6 \pm 0.8$ \\
\hline & $3(16)$ & & & 80 & $871 \pm 64$ & $30.7 \pm 0.8$ \\
\hline Carson et al., 2000 & 9 & Holstein & Prepubertal & 29 & $930 \pm 29$ & $22.2 \pm 0.9$ \\
\hline \multirow[t]{2}{*}{ Sejrsen and Foldager, 1992} & 8 & \multirow[t]{2}{*}{ Red Danish } & \multirow[t]{2}{*}{$90 \mathrm{~kg}$ to calving } & 50 & $498 \pm 12$ & $16.1 \pm 1.1$ \\
\hline & 8 & & & 30 & $475 \pm 12$ & $16.5 \pm 1.1$ \\
\hline \multirow[t]{2}{*}{ Hof and Lenaers, 1984} & 19 & \multirow[t]{2}{*}{ Friesian } & \multirow[t]{2}{*}{ Weaning to calving } & 82 & $687 \pm 91$ & $14.1 \pm 1.3$ \\
\hline & 17 & & & 19 & $643 \pm 78$ & $14.4 \pm 1.1$ \\
\hline
\end{tabular}

${ }^{1}$ Average daily gain and milk yield are group averages reported in the original papers.

${ }^{2}$ Numbers in parentheses indicate the number of heifers per diet. Heifers were pen-fed in 3 pens, which were considered to be the experimental units.

in the analysis, the objective of the experiment must have been to limit feed a diet for similar levels of ADG as a control diet. Therefore, the limit-fed diet would of necessity contain a greater energy density, as typically represented by a lower level of forage, than the control diet.

The animals, the timeframe over which treatments were imposed, and the conditions in which the animals were reared varied considerably among trials (Table 1 ). The response variables evaluated in the current analysis were ADG, milk production, milk fat yield and concentration, protein yield and concentration, milk solids concentration, and SCM (both calculated on a fat plus protein basis only; Tyrrell and Reid, 1965).

Substantial variation in milk production existed between the experiments because of the range of time and experimental conditions employed. In an initial analysis of the raw, weighted data, the random trial component accounted for over $97 \%$ of the variance. Biologically, when a production response varies over a wide range (because of genetic potential, nutritional management, differences between trials, and so on), the size of an absolute incremental response attributed to the imposition of a treatment may vary according to the observed response to the control diet (Fulkerson et al., 2008; for instance, a 1-kg increase in milk production is less meaningful for cows producing $30 \mathrm{~kg}$ of milk than for a cow producing $15 \mathrm{~kg}$ of milk). Given these considerations, data were reexpressed as relative changes for animals receiving the treatment diet over the control diet within each experiment, yielding 1 observation per experiment. The 2 limit-fed diets in the experiment of Hoffman et al. (2007) were pooled for analysis. To adequately account for variation in treatment differences, the standard errors of the means (SEM) that were reported with the data in the original studies were recalculated to standard errors of the difference (SED) of the relative response as follows:

$$
\mathrm{SED}=\frac{\sqrt{\left(\mathrm{SEM}_{1}^{2}+\mathrm{SEM}_{2}^{2}\right)}}{\text { response value of the control diet }} .
$$

The SED of the relative response was then used to weight the data to account for heterogeneous errors across studies: weight $=\mathrm{SED}^{-2}$ (St-Pierre, 2001). Inconsistency in response among trials was evaluated with Cochran's Q-test for heterogeneity (Cochran, 1954) and the proportion of total variation (within- and betweenstudy variation) that was attributed to heterogeneity, $I^{2}$ (between-study variation; Higgins and Thompson, 2002). Because the degree of heterogeneity in fixed effect response between trials was moderate for all responses measured, the underlying mean response was estimated using random effects meta-analytic procedures, with the moment estimate for the random effect calculated as described in DerSimonian and Laird (1986). The possibility of publication bias was evaluated with a funnel plot (Sterne and Egger, 2001).

The number of published experiments that have investigated the effects of limit feeding dairy heifers during the rearing period on subsequent milk production is currently limited. The conditions under which the existing experiments were conducted varied in time and management practices during the rearing and lactation periods. Whereas there was little evidence from the original studies that the type of feed provided in the rearing period influenced lactation performance, similar numerical trends existed across many studies, 

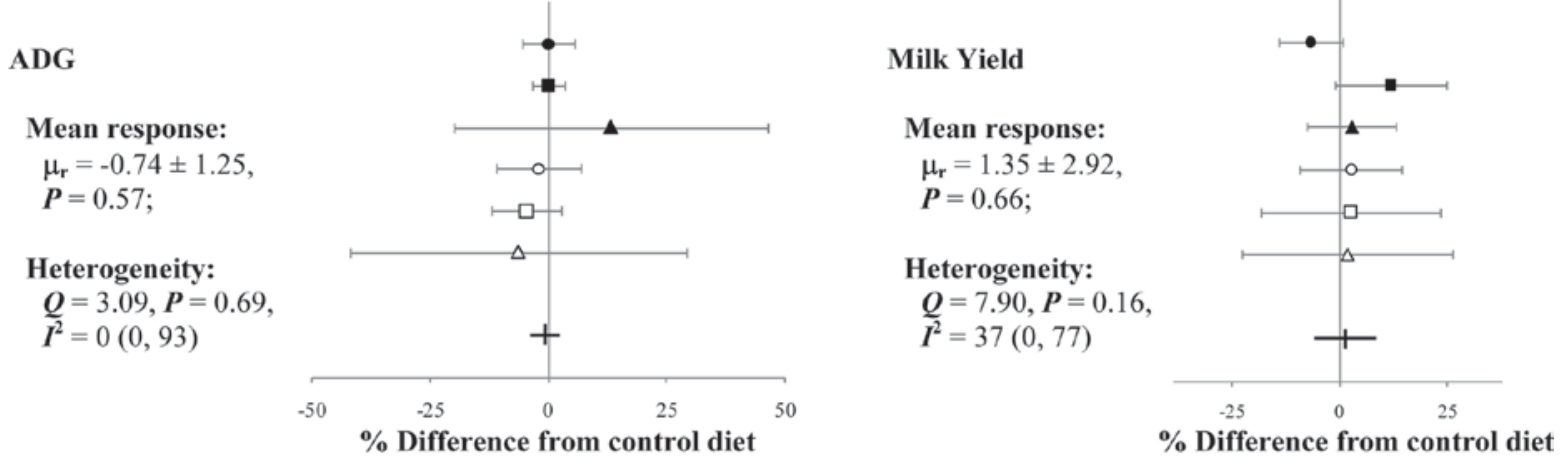

Fat, \%

Mean response:

$\mu_{\mathrm{r}}=-2.49 \pm 2.02$,

$\boldsymbol{P}=0.27$;
Heterogeneity:
$Q=7.05, P=0.22$, $I^{2}=29(0,74)$

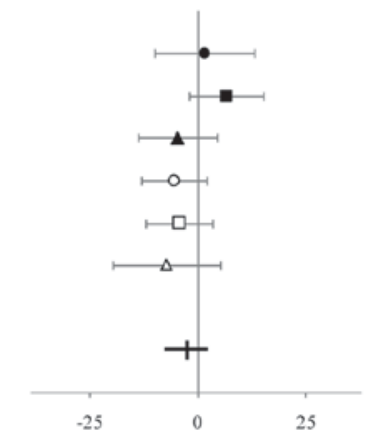

\section{Fat, kg}

Mean response:

$\mu_{\mathrm{r}}=-0.15 \pm 3.21$,

$\boldsymbol{P}=0.96$;
Heterogeneity:
$\boldsymbol{Q}=9.44, \boldsymbol{P}=0.09$,
$I^{2}=47(0,80)$

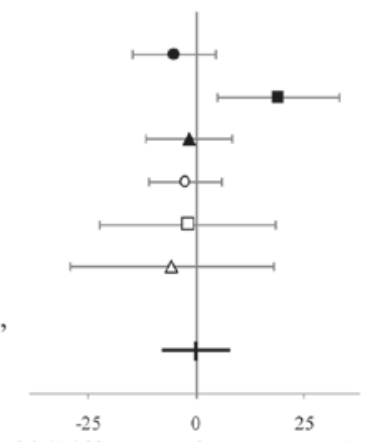

$\%$ Difference from control diet

$\%$ Difference from control diet

Protein, \%

Mean response:

$\mu_{\mathrm{r}}=-3.02 \pm 1.28$,

$\boldsymbol{P}=0.07$

Heterogeneity:

$Q=10.42, \boldsymbol{P}=0.06$,

$I^{2}=52(0,82)$

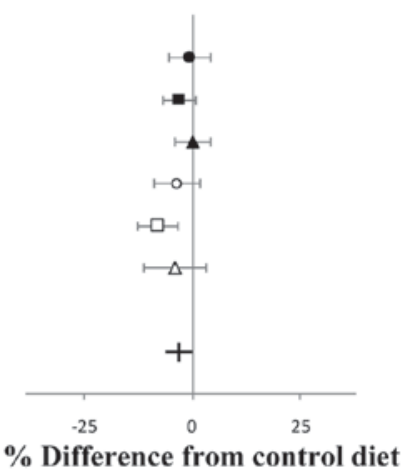

Protein, kg

Mean response:

$\mu_{\mathrm{r}}=0.63 \pm 2.16$,

$\boldsymbol{P}=0.78$;

Heterogeneity:

$\boldsymbol{Q}=4.92, \boldsymbol{P}=0.43$,

$I^{2}=0(0,55)$

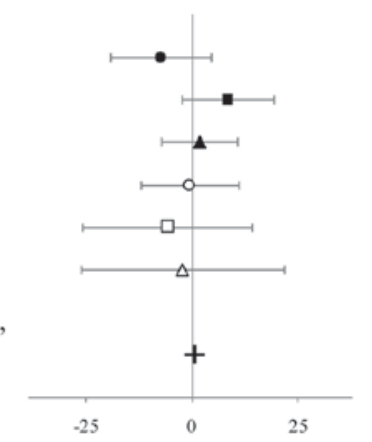

$\%$ Difference from control diet

Solids, \%

Mean response:

$\mu_{\mathrm{r}}=-1.55 \pm 0.77$,

$\boldsymbol{P}=0.10$;

Heterogeneity:

$Q=8.52, P=0.13$,

$I^{2}=41(0,78)$

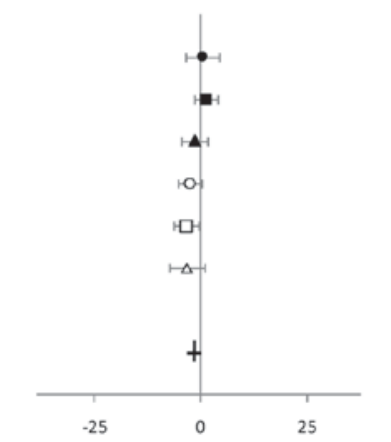

\section{SCM, kg}

Mean response:

$\mu_{\mathbf{r}}=-1.11 \pm 3.16$,

$$
\boldsymbol{P}=0.74
$$

\section{Heterogeneity:}

$\boldsymbol{Q}=8.26, \boldsymbol{P}=0.14$

$I^{2}=39(0,77)$

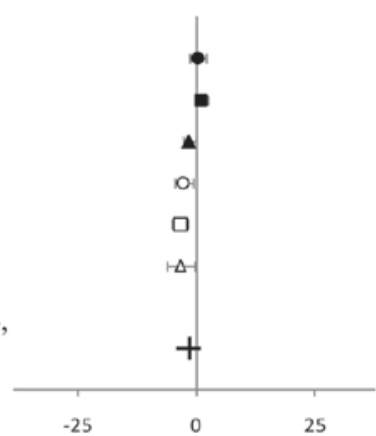

$\%$ Difference from control diet

$\%$ Difference from control diet

Figure 1. Proportional response and heterogeneity of ADG, milk, and milk components to limit feeding diets of higher energy density to dairy heifers for similar levels of ADG. Experiments: $\mathbf{-}=$ Lascano et al., 2009; $\mathbf{\square}=$ Zanton and Heinrichs, 2007; $\boldsymbol{\Delta}=$ Hoffman et al., 2007; $\bigcirc$ $=$ Carson et al., 2000; $\square=$ Sejrsen and Foldager, 1992; $\Delta=$ Hof and Lenaers, 1984. $+=$ mean response. $\mu_{\mathrm{r}}=$ random mean; Q $=$ Cochran's coefficient for heterogeneity; $I^{2}=$ the proportion of total variation (within- and between-study variation, attributed to heterogeneity (between study variation). 


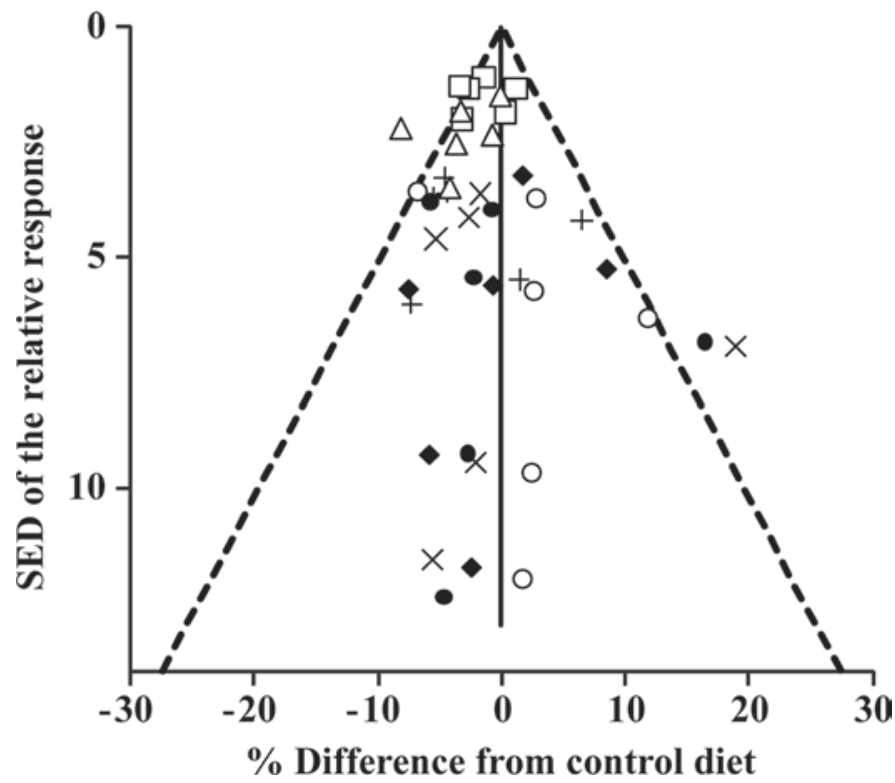

Figure 2. Funnel plot of the percentage difference of the treatment diet from the control diet versus the standard error of the difference (SED) of this relative response for productive outcomes for cows limitfed during the rearing period. Dashed lines are 95\% confidence intervals. Data are displayed for all outcome responses analyzed: $\bigcirc=$ milk yield; $+=$ milk fat percentage; $\times=$ milk fat yield; $\Delta=$ milk protein percentage; $\bullet=$ milk protein yield; $\square=$ milk solids percentage; $\bullet=$ SCM yield. Significant funnel plot asymmetry was not detected individually or collectively $(P>0.10)$.

potentially reflecting a lack of statistical power in these experiments or publication bias. To provide a statistical summary of these disparate experiments, a random model meta-analysis was conducted. The results of this analysis are presented in Figure 1. These results largely confirm the results of most of the individual experiments in that no significant differences in lactation performance were found between the limit-fed, lower forage diets and the higher forage control diets. Furthermore, no evidence of publication bias was found, suggesting that the results included in the current analysis are representative of the findings of all potential research that had been conducted on this subject (Figure 2). The only outcome variables that approached significance were those of milk protein percentage and milk solids percentage $(P=0.07$ and 0.10 , respectively), although these responses were largely dilution effects because the outputs of protein and solids in limit-fed heifers were not significantly different from those of heifers fed the control diets $(P>0.74)$. Heterogeneity of results between experiments (inconsistencies in findings) was low to moderate for the response variables evaluated in this experiment (Higgins et al., 2003), indicating that the results were reasonably consistent among the trials.

The ability to alter the milk production of cows by differences in nutritional management during the rear- ing period has been reported, but the largest effects observed have been mostly related to alterations occurring in prepubertal ADG (Zanton and Heinrichs, 2005). In experiments investigating the effects of differing prepubertal $\mathrm{ADG}$, treatments producing the $\mathrm{ADG}$ differences have often been attained by limit feeding or altering the forage level in the diet. These concurrent changes in feeding regimens do not allow inferences to be made about the effects of limit feeding a lower forage diet for a common ADG between groups. Studies used in this analysis, though limited in animal numbers per study, did employ equal ADG between groups and allow the opportunity to summarize the effects of the limit feeding systems. One study (Zanton and Heinrichs, 2009b) reported second-lactation production and reproduction data showing no differences between treatments for production, reproductive parameters, or culling age. The present study confirmed that limitfed heifers have similar production of milk and milk components in the first lactation across a wide range of management types and daily gains, further supporting the validity of this system as a viable alternative for raising heifers in situations where it may be appropriate or economical.

\section{REFERENCES}

Carson, A. F., A. R. G. Wylie, J. D. G. Mc Evoy, M. Mc Coy, and L. E. R. Dawson. 2000. The effects of plane of nutrition and diet type on metabolic hormone concentrations, growth and milk production in high genetic merit dairy herd replacements. Anim. Sci. 70:349-362.

Cochran, W. G. 1954. The combination of estimates from different experiments. Biometrics 10:101-129.

DerSimonian, R., and N. Laird. 1986. Meta-analysis in clinical trials. Control. Clin. Trials 7:177-188.

Fulkerson, W. J., T. M. Davison, S. C. Garcia, G. Hough, M. E. Goddard, R. Dobos, and M. Blockey. 2008. Holstein-Friesian dairy cows under a predominantly grazing system: Interaction between genotype and environment. J. Dairy Sci. 91:826-839.

Higgins, J. P. T., and S. G. Thompson. 2002. Quantifying heterogeneity in a meta-analysis. Stat. Med. 21:1539-1558.

Higgins, J. P. T., S. G. Thompson, J. J. Deeks, and D. G. Altman. 2003. Measuring inconsistency in meta-analyses. BMJ 327:557560.

Hill, S. R., K. F. Knowlton, R. E. James, R. E. Pearson, G. L. Bethard, and K. J. Pence. 2007. Nitrogen and phosphorus retention and excretion in late-gestation dairy heifers. J. Dairy Sci. 90:5634-5642.

Hof, G., and P. J. Lenaers. 1984. The importance of roughage in the rearing period on the feed-intake and performance of adult dairy cows. Livest. Prod. Sci. 11:287-302.

Hoffman, P. C., C. R. Simson, and M. A. Wattiaux. 2007. Limit feeding of gravid Holstein heifers: Effect on growth, manure nutrient excretion, and subsequent early lactation performance. J. Dairy Sci. 90:946-954.

Lascano, G. J., G. I. Zanton, F. X. Suarez-Mena, and A. J. Heinrichs. 2009. Effect of limit feeding high- and low-concentrate diets with Saccharomyces cerevisiae on digestibility and on dairy heifer growth and first-lactation performance. J. Dairy Sci. 92:5100-5110.

Moody, M. L., G. I. Zanton, J. M. Daubert, and A. J. Heinrichs. 2007. Nutrient utilization of differing forage-to-concentrate ratios by growing Holstein heifers. J. Dairy Sci. 90:5580-5586. 
Sejrsen, K., and J. Foldager. 1992. Mammary growth and milk production capacity of replacement heifers in relation to diet energy concentration and plasma hormone levels. Acta Agric. Scand. A Anim. Sci. 42:99-105.

St-Pierre, N. R. 2001. Invited review: Integrating quantitative findings from multiple studies using mixed model methodology. J. Dairy Sci. 84:741-755.

Sterne, J. A. C., and M. Egger. 2001. Funnel plots for detecting bias in meta-analysis: Guidelines on choice of axis. J. Clin. Epidemiol. 54:1046-1055.

Tyrrell, H. F., and J. T. Reid. 1965. Prediction of the energy value of cow's milk. J. Dairy Sci. 48:1215-1223.
Zanton, G. I., and A. J. Heinrichs. 2005. Meta-analysis to assess effect of prepubertal average daily gain of Holstein heifers on firstlactation production. J. Dairy Sci. 88:3860-3867.

Zanton, G. I., and A. J. Heinrichs. 2007. The effects of controlled feeding of a high-forage or high-concentrate ration on heifer growth and first-lactation milk production. J. Dairy Sci. 90:3388-3396.

Zanton, G. I., and A. J. Heinrichs. 2009a. Digestion and nitrogen utilization in dairy heifers limit-fed a low or high forage ration at four levels of nitrogen intake. J. Dairy Sci. 92:2078-2094.

Zanton, G. I., and A. J. Heinrichs. 2009b. Review: Limit-feeding with altered forage-to-concentrate levels in dairy heifer diets. Prof Anim. Sci. 25:393-403. 